\title{
A PÁTRIA DE CHUTEIRAS ESTÁ DESAPARECENDO?*
}

\author{
MS. TIAGO LISBOA BARTHOLO
}

Doutorando do Programa de Pós-Graduação em Educação da

Universidade Federal do Rio de Janeiro (UFRJ)

Coordenador e professor do Setor Curricular de Educação Física

do Colégio de Aplicação da UFRJ (Rio de Janeiro - Brasil)

E-mail: tbartholo8I@hotmail.com

\section{DR. ANTONIO JORGE GONÇALVES SOARES}

Doutor em educação física pela UGF

Professor do Programa de Pós-Graduação em Educação da UFRJ (Rio de Janeiro - Brasil)

Bolsista de produtividade do CNPq

E-mail: ajsoares@globo.com

\author{
DR. MARCO ANTONIO SANTORO SALVADOR \\ Doutor em educação física pela UGF \\ Professor da Faculdade de Educação da Universidade do Estado do Rio de Janeiro (UERJ) \\ (Rio de Janeiro - Brasil) \\ E-mail:marcosantoro@uol.com.br
}

MS. FELIPE DI BLASI

Mestre em educação física pela UGF

E-mail: philoguitarra@yahoo.com.br

\begin{abstract}
RESUMO
O objetivo do artigo é analisar os textos publicados na imprensa sobre as Copas do Mundo de futebol de 1958 e 1962, e compará-los com os textos sobre a Copa de 2002, buscando explicitar possíveis descontinuidades no tratamento desses eventos esportivos. Utilizamos como fontes as edições do Jornal do Brasil durante as três Copas analisadas. A análise das narrativas jornalísticas referentes ao "estilo nacional" de jogar futebol apresenta continuidade. Ora temos o estilo de ginga e dribles valorizado, quando eficaz, ora o temos como negativo diante das derrotas. As narrativas das Copas de 1958 e 1962 não têm um caráter homogêneo ao tratar o futebol brasileiro, mudando o foco do debate de acordo com a superação das dificuldades do time.
\end{abstract}

PALAVRAS-CHAVE: Identidade nacional; futebol; imprensa; história das Copas.

* Auxílio financeiro CNPq - bolsa de produtividade em pesquisa (PQ) e bolsa de mestrado. Não houve conflitos de interesses para a realização do presente estudo. 


\section{INTRODUÇÃO}

No Brasil, o debate acadêmico sobre identidade e esporte sempre teve no futebol um campo privilegiado para as suas interpretações. $\bigcirc$ futebol, por toda a dimensão que alcançou no Brasil - a ponto de frequentemente ser comparado a uma religião pelos meios de comunicação de massa -, apresenta-se como um campo fértil para a análise das narrativas nacionalistas e dramatizações sobre o nacional, produzidas a partir desse fenômeno.

As dramatizações presentes nas disputas esportivas internacionais seriam uma "nova janela" para observar o nacional. Nesse sentido, o esporte, mas não somente o esporte, é uma "zona livre" - "espacios para la mezcla, la aparición de híbridos, la sexualidad y la exaltación de desempeños físicos [...] permiten la articulación de lenguajes y prácticas que pueden desafiar un dominio público oficial y puritano" (ARCHETtI, 2003, p. 42). As "zonas livres" tornaram-se espaços para exercitar a criatividade e para a construção de (novas) identidades. Nesse mercado transnacional das identidades nacionais, países como o Brasil, a Argentina e Cuba se notabilizaram interna e externamente por exportar corpos, ritmos e comidas exóticas. Em um mundo constituído por Estados-nação, a semelhança (todos são nações) acompanha a diferença e a exclusão - só existe um Brasil (ARCHETTI, 2003).

As competições esportivas internacionais, como os Jogos Olímpicos Modernos ou a Copa do Mundo de Futebol, tornaram-se espaços para a construção da diferença em um novo "mercado" global: o das práticas corporais esportivas.

La globalización temprana del deporte no debe verse como un proceso necesario de homogeneización, sino como un espacio en donde producir imaginarios, símbolos y héroes que establezcan discontinuidades. Las reglas universales y las prácticas son uniformes pero los resultados impulsan no solo las diferencias sino a pensarlas como tales (ARCHetTI, 200 I, p. I4).

Este estudo' tem como objetivo dar continuidade e aprofundar o debate iniciado por Helal e Soares no artigo "O declínio da pátria de chuteiras: futebol e identidade nacional na Copa do Mundo de 2002"2. Nesse trabalho, os autores fizeram uma análise sobre as narrativas da imprensa nos suplementos esportivos do Jornal do Brasil durante a Copa do Mundo de futebol de 2002. Os autores

I. Não houve conflitos de interesses para a realização do presente estudo. Este estudo foi financiado pelo CNPq, Edital Humanidades, proc. n. 40/846/2007-5.

2. Este artigo foi apresentado em Recife na XII Reunião Anual da Associação de Pós-Graduação em Comunicação - Compós, 2003. 
trabalharam com a hipótese de que o processo conhecido como globalização ${ }^{3}$ estaria "deslocando" ou esvaziando o ufanismo nacionalista presente nas narrativas jornalísticas quando o assunto é a seleção de futebol.

A análise empreendida por Helal e Soares (2003) indica que a mídia impressa apresenta nova perspectiva no tratamento do tema sobre a Copa de 2002, em função dos complexos movimentos da globalização presentes no campo do esporte. Por essa razão, acabam por encontrar mudanças de foco na linha editorial do esporte, pois acreditam que a ênfase dada ao tema da nação passa a perder espaço para temas de caráter mais específico do esporte e de generalidades em torno do evento. Por exemplo, os jornais apresentam matérias sobre os torcedores da seleção brasileira que nada entendem de futebol, destacando que esse meio começa a dar espaço para a crítica ao futebol do passado. Nessa direção apontam a coluna escrita pelo jornalista Aydano André Motta intitulada "Aos estetas do futebol a vapor" (JORNAL DO Brasil, 23 jun. 2002, Caderno de Esportes, p. 3), em que o colunista tece críticas às interpretações feitas ao futebol brasileiro a partir das memórias do passado (HELAL; SOARES, 2003). Todavia, os próprios articulistas apontam para possíveis lacunas ou bias de suas análises:

Temos que admitir que estamos partindo do pressuposto, presente em vários estudos sobre futebol e identidade, que a narrativa jornalística tinha no passado, principalmente a partir da Copa de 50, um caráter mais homogêneo e totalizante em torno do projeto nacional. No entanto, poderíamos questionar até que ponto as narrativas jornalísticas sobre as participações nesses eventos assumiu esse caráter homogeneizante no passado. Pois, se partimos de outro pressuposto presente nos estudos culturais que afirma que não existe cultura pura e nem homogênea, e que tais construções são frutos de embates, pensamos que seja necessário que revisitemos os jornais de outras copas com o olhar voltado para as transformações da narrativa esportiva no sentido comparativo para a construção de uma sociogênese desta especialidade jornalística (idem, p. 12).

A lacuna identificada acima nos fornece a suspeita de que as interpretações de Helal e Soares (idem) não possuem a necessária base de dados para balizar a continuidade ou a descontinuidade dos sentimentos identitários no espaço da imprensa escrita. No sentido de aprofundar essa questão, realizamos uma análise comparando as narrativas da imprensa escrita sobre as Copa do Mundo de 1958 e 1962 com as narrativas da Copa de 2002. O critério para escolha das Copas

3. Neste trabalho globalização deve ser entendida como "[...] processos que atuam em escala global, que atravessam fronteiras nacionais, integrando e conectando comunidades e organizações em novas combinações de tempo-espaço, tornando o mundo, em realidade e em experiência, mais interconectado" (HALL, 2003, p. 67). 
de 1958 e 1962 se deu em função de que nessas competições o Brasil conseguiu consagrar-se campeão e bicampeão consecutivamente. As fontes utilizadas foram as edições do Jornal do Brasil durante as Copas de 1958 e 1962, o mesmo veículo tomado como fonte por Helal e Soares (idem). Utilizamos a análise temática de conteúdo para guiar nossas análises (BARDIN, 1977). Realizamos leituras e análises das matérias jornalísticas que trataram as Copas de 1958 e 1962 e contrastamos com as matérias publicadas durante a Copa de 2002.

Assim, partimos do seguinte pressuposto: se as análises de Helal e Soares (idem) estiverem corretas sobre 2002, os eventos de 1958 e 1962 foram matériaprima para a imprensa escrita maximizar os sentimentos ufanistas e nacionalistas sobre o futebol. Essas Copas teriam impulsionado o futebol brasileiro a se afirmar como potência no cenário internacional.

\section{A COPA DO MUNDO DE FUTEBOL 2002}

Antes de iniciarmos a análise das narrativas da imprensa sobre o desempenho da seleção nacional dentro do evento, iremos mostrar, de forma breve, como foi o caminho da equipe para chegar até essa competição ${ }^{4}$. A seleção brasileira vivenciou muitas dificuldades para se classificar, só garantindo a vaga no último jogo das eliminatórias. Além disso, o técnico Luis Felipe Scollari abriu mão, apesar do intenso clamor popular, de convocar Romário ${ }^{5}$. $\bigcirc$ esquema tático escolhido pelo técnico, com a utilização de três zagueiros, fugia aos padrões utilizados pelos técnicos que dirigiram a seleção brasileira no passado, sendo por isso alvo de pesadas críticas por parte da mídia 6 . Esses fatores contribuíram para criar um clima de desconfiança em relação ao time que representaria a nação.

De maneira geral, as matérias sobre a Copa do Mundo de 2002, segundo Helal e Soares (idem), se concentraram primordialmente em aspectos técnicos e táticos do jogo. Reportagens que traziam elementos ligados à identidade nacional apareceram de forma tímida, estando em sua maioria concentradas em crônicas e colunas jornalísticas. Porém é possível notar um aumento de matérias que retratam

4. Todas as seleções que participaram da Copa do Mundo passaram pelas chamadas eliminatórias regionais, em que as seleções jogam com adversários de seus próprios continentes, buscando uma vaga na fase final da competição.

5. Devemos lembrar que Romário foi mencionado pela imprensa como o grande responsável pela vitória do Brasil na Copa do Mundo de 1994. Sua ausência na Copa da França (1998) se deu por contusão.

6. Muitas dessas críticas falam de uma possível europeização do modo de nossa seleção atuar, uma vez que esse esquema tático era bastante utilizado por técnicos europeus. 
o "estilo nacional", na medida em que a competição avançava e que o Brasil ia aparecendo como um possível candidato ao título (idem).

Helal e Soares (idem) afirmam que as narrativas jornalísticas da Copa de 2002 são ambíguas e dúbias, principalmente até a seleção começar a demonstrar a possibilidade de disputar o título. Se por um lado o jornal apresentava uma linha editorial que fornecia análises mais distanciadas sobre o evento, dando voz a especialistas e analistas (por exemplo, o Caderno Ideias - JORNAL DO BRASIL, 25 maio 2002 - trazia a análise de um filósofo, um geógrafo e um psicanalista), por outro as colunas de Armando Nogueira e de Joaquim Ferreira dos Santos eram repletas de narrativas que exaltavam o "estilo nacional" e suas singularidades.

Ao longo de toda a cobertura da Copa, inúmeras matérias traziam como foco principal os "craques internacionais". Muitas delas abordavam assuntos que não eram referentes à Copa, como a manchete "O cabelo deles não nega"7 (JORNAL DO BRASIL, 25 jun. 2002, Caderno de Esportes, p. I), que destacava os diferentes penteados dos jogadores que influenciariam a moda ao redor do mundo. Esta talvez possa ser apontada como uma mudança em relação à cobertura das Copas do Mundo de 1958 e 1962. Hoje, atletas como David Beckham e Ronaldo, apenas para citar os mais midiáticos no momento, são contratados não apenas pela sua competência esportiva, mas também pela imagem positiva que possuem. Empresas multinacionais dos mais diversos setores da economia vinculam seus produtos e marcas às imagens dos atletas - e por extensão do esporte - na busca pela maximização nas vendas, e é aí que reside a diferença: o tema que os jornais abordam não se limita ao jogo ou à competência técnica dos jogadores. Hoje os ídolos possuem mais voz, imagem e espaço na mídia do que no passado e se tornaram celebridades em qualquer espaço que circulam. Essa nova condição parece deslocar a cobertura do evento por parte da imprensa no ano de 2002, em relação às Copas de 1958 e 1962.

Noutra direção, não se pode perder de vista que o indivíduo, o herói, engloba e representa a nação ou a cidade na história do Ocidente. Porém essa possível mudança de foco não apresenta fortes marcas de descontinuidade identitária, como podemos deduzir das análises de Helal e Soares (2003). As duas manchetes que foram veiculadas no dia seguinte à vitória final da equipe dão o tom: "Mundo volta a reverenciar o Brasil" (JoRnAL do BRASIL, I o jul. 2002, Caderno de Esportes, p. 20) e "O rei do mundo: Ronaldinho faz dois gols na final, confirma a artilharia da Copa

7. Devemos lembrar que esta expressão o "Teu cabelo não nega" indica a constituição afro-brasileira de nossa população, muito embora a matéria utilize esse jargão para referir-se aos diferentes penteados e cortes de cabelo dos jogadores de diferentes seleções.

8. Para um maior aprofundamento, ver Whannel (2002). 
e dá a volta por cima" (idem, p. I). Devemos destacar que a matéria de capa do jornal faz referência ao jogador Ronaldo, evidenciando um destaque maior para o feito individual do atleta. Não devemos perder de vista que ele é brasileiro, e isso é enfatizado pelos jornais, mas também que a imagem de Ronaldo está associada à Nike e a outras marcas nacionais e internacionais. Esse processo de "pluralização" de identidades, para além das fronteiras nacionais, é que parece ser novo. Entretanto, a nação ainda é um forte símbolo e mote dessas matérias.

Outra novidade é que as marcas patrocinadoras, mais que o merchandise, se tornam notícia. Na final entre Brasil e Alemanha, uma matéria com quatro colunas, ocupando quase meia página, fazia a seguinte chamada: "A grande final das marcas: na disputa entre Adidas e Nike, partida vai terminar sem perdedores" (JORNAL DO BRASIL, 30 jun. 2002, p. 9). Luciano Kleiman, gerente de marketing da empresa de material esportivo Adidas no Brasil afirma: "Nosso projeto não depende de resultados das equipes patrocinadas. Estávamos presentes em 58\% dos jogos nos uniformes e, em todos eles, com a bola oficial e em placas publicitárias" (idem, ibidem) 9 .

Na parte final de seu artigo, Soares e Helal afirmam:

O futebol, pensamos, ainda opera como um mecanismo integrador/totalizador. No entanto, os agentes do universo futebolístico, não mais trabalham no sentido desta associação, ou pelo menos da maneira clara e conscientemente dirigida como na época do Mário Filho (2003, p. 13).

A seguir, faremos uma análise das reportagens sobre a Copa do Mundo de 1958, realizada na Suécia - palco do primeiro título mundial do futebol brasileiro - e das reportagens sobre a Copa de 1962, realizada no Chile, buscando mais dados que nos auxiliem a refletir sobre a questão proposta.

\section{COPA DO MUNDO DE FUTEBOL DE 1958}

A seleção brasileira de futebol, que se preparava para a disputa da Copa do Mundo na Suécia, em 1958, fez uma série de jogos amistosos dentro do Brasil, visando ganhar entrosamento e responder às últimas dúvidas do técnico Feola quanto à escalação ideal do time. A seleção realizou partidas contra as seleções do Paraguai e da Bulgária, e contra o time do Sport Club Corinthians Paulista.

9. A Folha de S.Paulo, durante as Olimpíadas de 1996, apresentou o ranking de medalhas dos patrocinadores das equipes nacionais na matéria "Negócios: patrocinador oficial leva mais medalhas de ouro nos jogos que consagram as grandes empresas esportivas" (I I ago. 1996, Caderno de Esportes, p. 10). 
Antes de começarmos a narrar as matérias veiculadas no Jornal do Brasil, durante a participação brasileira na Copa de 1958, cabe ressaltar a ênfase da imprensa em relembrar a derrota sofrida pela seleção em 1950, no Maracanã. Das 39 matérias publicadas durante a realização da competição, 9 faziam menção à derrota brasileira naquela competição ${ }^{10}$.

Na fase final de preparação, antes do embarque para a Suécia, saiu a matéria com o título: "Psicólogo Carvalhais: única inovação no scratch - Como está trabaIhando a tremedeira" (JoRnal do BrasiL, 28 maio 1958, Segundo Caderno, p. I). Os jornais na época, apesar de apontarem a seleção brasileira como tecnicamente bem preparada e de preverem uma boa campanha, temiam que se repetisse o ocorrido em 1950. A derrota para os uruguaios é relembrada"!.

Essa dúvida quanto à capacidade de vencer do selecionado brasileiro se mostra presente, inclusive, nas manchetes que antecedem a final da Copa do Mundo contra a seleção da Suécia:

Depois do jogo com a França, em Solka, um jornalista francês nos encontrou e disse: - Vocês venceram porque a equipe de vocês é mais forte e melhor. Creio que vocês serão campeões do mundo. Em futebol qualquer afirmação é perigosa. Para nós, brasileiros então, é mais perigosa ainda, já que ainda está bem vivo o exemplo de 1950, quando não podíamos perder o título e perdemos (JORNAL DO BraSIL, 27 maio 1958, Segundo Caderno, p. I).

Cabe lembrar que, até a disputa da Copa de 1958, o Brasil não havia conquistado nenhum título em Copas do Mundo, apesar de ser reconhecido como formador de seleções de qualidade. Os dados coletados sobre os campeões e vice-campeões de Copas do Mundo mostram que seleções europeias estiveram nas finais em seis oportunidades, conquistando três títulos, enquanto seleções sulamericanas estiveram por quatro vezes nas finais, conquistando dois títulos.

Dias antes da estreia da seleção brasileira na Copa, o Jornal do Brasil trouxe a manchete: "Brasil deve jogar de primeira sem fazer 'firulas' para fazer figura" (idem, ibidem). "As imagens vinculadas àquilo que se denominou 'estilo brasileiro de futebol' são as da alegria, da improvisação, dos floreios, dos dribles, do toque de calcanhar, enfim, das firulas" (SOARES; LovisOlo, 2003, p. 130). O jogo "de primeira" pode ser interpretado como uma característica do futebol europeu, no qual o aspecto tático parece ser mais valorizado que as habilidades individuais. A matéria naquele contexto

10. Os dias em que as matérias foram publicados são: 25, 26 e 28 de maio de 1958; e 4, 5, 6, 7, I I, 24 e 27 de junho de 1958. Todas veiculadas no Jornal do Brasil.

I I. Para um maior aprofundamento, ver Vogel (1982), "A tragédia do Maracanã". 
questionava a eficácia da identidade do futebol brasileiro diante do europeu. Soares e Lovisolo (idem) demonstram que essa tensão sobre o estilo brasileiro está presente no espaço da imprensa escrita, pelo menos desde a década de 1920.

Elementos ligados à identidade nacional aparecem de forma tímida nas reportagens e, muitas vezes, implícitos em matérias que falam sobre a diferença do estilo do futebol sul-americano diante do estilo europeu; nesse caso, o estilo sul-americano engloba o nacional. Convém ressaltar que as matérias que traziam discursos com elementos ligados ao "estilo nacional" são aquelas com as opiniões de técnicos ou jornalistas estrangeiros. Podemos interpretar esse fato como uma busca de afirmação de nossa capacidade técnica por meio da opinião de técnicos e jornalistas estrangeiros. Aqui a imprensa recorre ao velho mecanismo de convocar os de "fora", por, supostamente, terem mais distância para avaliar a competência da seleção que os de "dentro". Devemos lembrar que o continente europeu detinha a hegemonia em conquistas de títulos em Copas.

Assim como ocorreu na análise de Soares e Helal (2003) sobre a Copa de 2002, as narrativas jornalísticas com discursos identitários foram ganhando força à medida que a seleção avançava para as etapas finais da competição. Jornalistas brasileiros passaram a acompanhar os estrangeiros e a valorizar a técnica diferenciada ou a "habilidade inata" dos jogadores brasileiros. O colunista Célio de Barros, após a vitória brasileira sobre a França nas semifinais da competição, se rende à capacidade do selecionado brasileiro:

[...] A vitória alcançada pela equipe brasileira corresponde, sem favor algum, à superioridade que vem mantendo desde a primeira partida em que triunfou brilhantemente sobre o quadro da Áustria. [...] A vitória de ontem, que os nossos denodados patrícios impuseram aos franceses, é daquelas que não admite a mais leve contestação, pois foi fruto de uma superioridade e uma técnica indiscutíveis e que serviu de belíssima demonstração do que, na realidade, vale o futebol brasileiro, sem dúvida alguma entre os melhores de todo o mundo.

E toda essa multidão que ouviu as irradiações da grande partida fremiu, delirante de entusiasmo, quando a mesma terminou deixando os brasileiros a um passo somente do tão desejado e ansiosamente esperado título de campeão do mundo (Jornal Do Brasil, 25 jun. 1958, Segundo Caderno, p. I).

No dia 27 de junho de 1958, o jornal estampa na capa, pela primeira vez na cobertura dessa Copa, uma reportagem sobre a seleção brasileira. A conquista da vaga na final tornou o futebol importante na conjuntura do país.

A coluna de Célio de Barros, dois dias antes da final, traz a manchete: "Tipicamente futebol sul-americano" (JoRnAL do BrasIL, 28 jun. 1958, Segundo Caderno, p. I). Observemos que aqui, mais uma vez, a identidade brasileira aparece englobada 
na sul-americana. Na coluna, o autor continua um debate que o técnico argentino Stabile iniciou, buscando uma resposta para a pergunta: Quem possui o melhor futebol, os europeus ou os sul-americanos? '2. Esse técnico afirmava que houve uma americanização do futebol europeu, assim como uma europeização das seleções sulamericanas, e atribui esse fato ao intercâmbio de técnicos e das próprias excursões feitas pelas seleções na fase de preparação para a competição.

Os argumentos do técnico argentino, citado por Célio de Barros, indicam uma espécie de difusionismo ou intercâmbio no espaço do futebol, e essa passagem dá indícios para questionar o argumento de um estilo nacional de futebol. Estamos, porém, interessados na reação do colunista brasileiro, que afirma: "Na América do Sul joga-se o futebol de acordo como mandam as regras em todo o mundo, mas as características particulares de cada qual nada têm de europeias e são tipicamente de nosso continente" (idem, ibidem) ${ }^{13}$.

$\bigcirc$ debate neste momento não tem contornos de elementos da identidade nacional, mas de uma identidade de um continente. Temos que matizar a análise: se na Copa de 2002 o debate em torno do "estilo nacional" de futebol está presente em algumas matérias, em 1958 o estilo mais do que nacional é sul-americano, quando o "outro" é a Europa. Cabe lembrar que o Brasil ainda não havia conquistado nenhum título mundial e apenas o Uruguai havia conquistado duas Copas.

$\bigcirc$ dia $1^{\circ}$ de julho de 1958 é marcado pelas manchetes que trazem a confirmação da vitória da seleção brasileira. A capa do jornal traz a manchete "Chegam amanhã os campeões do mundo: também não é feriado" (JORNAL DO BRASIL, I ${ }^{\circ}$ de julho de 1958, p. 7), e, nas seções internas, inúmeras matérias sobre a inédita vitória: "Antologia da vitória" (idem, ibidem), "Uma pequena fortuna para cada campeão" (idem, ibidem), "O mundo inteiro aprova: BRASIL CAMPEÃO" (idem, p. I). Todas traziam entrevistas amplamente vinculadas aos valores nacionais e reforçavam os sentimentos identitários da nação, segundo o conceito de identidade legitimadora ${ }^{14}$ de Castells ( 1 999), nas quais personalidades falavam de forma entusiasmada sobre o triunfo da seleção:

É o Brasil novo que começa a conquistar as suas vitórias, é o Brasil de Brasília que, plantado no coração da pátria, têm agora um espírito novo a dirigir-lhe os destinos - presidente Juscelino Kubitschek. Os onze moços brasileiros que dançaram o samba com a bola

12. Nas semifinais dessa competição, havia três representantes europeus contra um sul-americano.

13. Observe que o debate do estilo está aqui presente. Cf. Soares e Lovisolo (2003).

14. Esse conceito, segundo o autor, é introduzido pelas instituições dominantes da sociedade no intuito de expandir e racionalizar sua dominação em relação aos atores sociais, tema este que está no cerne da teoria de Sennett, e se aplica a diversas teorias do nacionalismo. 
aos pés deram aos políticos, aos militares, aos técnicos - autênticos ou falsos - a todo a gente, uma bela lição. De coesão, de disciplina, de esforço de compostura, de animação, de perícia e, sobretudo, de um verdadeiro patriotismo - deputado Carlos Lacerda, jornalista e líder da UDN. Foi uma grande afirmação do Brasil no âmbito internacional - professor Clóvis Salgado, ministro da Educação. A vibração do povo, a sua manifestação de regozijo, e a alegria dos corações brasileiros repontam como a eterna esperança que anima os verdadeiros patriotas, cientes e conscientes de sua nacionalidade, na afirmação eloquente de uma raça - general Oromar Osório. Negavam o caráter de Didi. E, no entanto, este homem jogou da primeira batalha, com uma seriedade, uma autoridade, uma grandeza pessoal de Abraão Lincon - teatrólogo Nelson Rodrigues (JORNAL DO BrasIL, I 0 jul. I 958 , p. 7, grifo nosso).

As narrativas da imprensa, em sua grande maioria, mostram a vitória da seleção brasileira como um triunfo da nação. Seria o jovem país que começava a mostrar que é capaz de competir e, principalmente, ganhar dos países mais desenvolvidos economicamente. Podemos observar, no texto acima, como se funde, no âmbito do discurso, o estilo de jogo imaginado como nacional - valorizado quando é eficaz ${ }^{15}$-, a ideia de pátria, patriotismo e nação, representados na vitória, com o discurso da disciplina, do esforço e da dedicação. $\bigcirc$ futebol malandro, gingado e sambado, aparece com a disciplina do "caxias" no contexto da vitória. Embora o jornal dê voz aos diferentes personagens da vida política e cultural, é necessário destacar que a edição das falas acaba por formatar um painel dos sentimentos e análises das eminentes opiniões acima. A edição é intencional e se pretende fixar como memória: "Estas manifestações - colhidas aqui e ali na imprensa, como nos anais do Congresso - são um verdadeiro sinal dos tempos e nós as publicamos como subsídios ao historiador do futuro" (idem, ibidem). Aqui fica explícita a consciência do jornal como guardião da memória.

Nessas matérias, o que parece ficar claro é a importância dada aos comentários dos jornais estrangeiros quanto à nossa capacidade de jogar futebol. Isso talvez esteja intimamente ligado ao fato de que, antes de 1958, o Brasil jamais havia sido campeão. As narrativas de 2002, quando o Brasil já era o maior vencedor da história das Copas, se concentram na questão da perda ou afirmação do "estilo nacional".

\section{COPA DO MUNDO DE FUTEBOL DE 1962}

Os amistosos feitos pela seleção brasileira, visando à preparação para a disputa da Copa do Mundo de 1962, no Chile, foram alvo de críticas por parte

15. O jornalista, no dia 27 de maio de 1958, afirma que o Brasil não podia jogar com firulas, se almejasse avançar na Copa. 
da imprensa desportiva local, que destacava a falta de padrão de jogo por parte do time. Entre esses amistosos podemos destacar os dois jogos realizados contra o País de Gales.

No dia da estreia na competição, o Jornal do Brasil trazia as manchetes "Brasil estreia hoje com time campeão de 58" (JORNAL DO BRASL, 30 maio 1962, p. I), "Brasil trilha no Chile o mesmo caminho que o levou à vitória em 58" (idem, p. 12) e "Brasil estreia com o time campeão do mundo" (idem, p. 13), fazendo referência às glórias alcançadas quatro anos antes na Suécia. Ressalta-se que as narrativas que antecediam o campeonato de 1958 faziam referência à derrota de 1950, enquanto as narrativas que antecederam a Copa no Chile referenciavam o Brasil campeão do mundo quatro anos antes. Se compararmos com 1958, essa mudança de postura por parte da imprensa, ao noticiar a seleção como um time vitorioso, traz uma diminuição do número de matérias e entrevistas com técnicos e jornalistas estrangeiros sobre a real capacidade do selecionado de vencer uma competição de nível mundial. Na cobertura da Copa de 1958, 33,3\% das reportagens ( 13 em um universo de 39) traziam entrevistas com técnicos, jogadores ou jornalistas estrangeiros. Já em 1962 são 6,6\% (5 em um universo de 75). É como se a imprensa agora não precisasse tanto da opinião e legitimação dos estrangeiros sobre a capacidade do brasileiro no futebol.

O início da Copa mostra certa divisão de opiniões quanto à capacidade do selecionado brasileiro. A matéria "Brasil abre caminho entre otimismo e o pessimismo no Chile" resume as diferentes expectativas sobre a seleção:

O Brasil jogou mal para os pessimistas, mas jogou bem para os otimistas assim porque todos sabem que o fenômeno do nervosismo na estreia ainda não nos abandonou. [...] Todos estes fatores porém foram superados pela grande categoria e força de vontade dos jogadores, que depois de um primeiro tempo em branco um tanto intranquilizador partiram para uma vitória fácil, terminada em boa exibição (Jornal Do Brasil, I jun. 1962, p. II).

Assim como em 1958 e 2002, as narrativas com elementos identitários foram ganhando espaço à medida que o Brasil avançava na competição. Observamos também que a ideia do descrédito da seleção, antes do início das competições, parece ter-se tornado um mote jornalístico para tratar esse tipo de evento. Essas narrativas, porém, não explicitam apenas o "estilo nacional", uma vez que também abrem espaço para o elogio à responsabilidade e à capacidade de organização da equipe.

Nessa competição o Brasil perdeu Pelé, seu mais importante jogador, no segundo jogo. Esse episódio traz em nossa análise duas consequências ambíguas nas narrativas jornalísticas: a) abre caminho para que Garrincha assuma o posto de principal jogador brasileiro na competição, sendo considerado um jogador "fantástico, 
incrível, extraordinário" (Jornal do Brasil, 12 jun. 1962, p. I); b) traz uma exaltação à capacidade de organização do time, que, mesmo sem seu maior craque, é capaz de ganhar. É a confirmação do futebol brasileiro.

A sorte roubou ao Brasil este jogador fabuloso chamado Pelé, mas ainda não nos tirou, que conquistamos na Suécia. A seleção brasileira perdeu um jogador, mas não perdeu sua condição de campeão, sua categoria invejável, seu futebol que é o melhor do mundo (Jornal do Brasil, 6 jun. 1962, p. 13).

Assim como aconteceu em 1958, a imprensa noticia cada vitória do time como um triunfo da nação. As matérias falam sobre a alegria que tomava conta das ruas a cada vitória do time, sentimento este que só aumenta à medida que a final da competição se aproximava. Os dias que antecedem a grande final trazem as manchetes: "O último dribling" (Jornal Do Brasil, 17 e I 8 jun. 1962, p. I I), "Copa fez justiça ao simples e diabólico seu Mané Garrincha" (idem, p. 23), "Brasil decide o título sem mudar o time" (idem, p. 24) e "Brasil enfrenta um time que joga com a cabeça e o coração" (idem, ibidem). Essas matérias destacam tanto o talento individual brasileiro, encarnado nessa Copa na figura de Garrincha, como a grande campanha que o time vinha fazendo, apontando o Brasil como o favorito ao título. Garrincha torna-se paradigma da identidade de nosso futebol alegre e gingado (BARTHOLO; SOARES, 2009).

O Brasil vence o jogo e a vitória é narrada como mais um triunfo da nação. A vitória passa a ser símbolo de uma nação que busca reconhecimento e tem no futebol um instrumento para mostrar suas qualidades.

Outros povos se afirmam de outros modos. Devemos respeitá-los e, inclusive, estimulá-los. Mas devemos respeitar a nossa maneira em tudo, e por tudo peculiar (bem brasileira como diz a expressão á consagrada) e não perdemos em desânimo e em sentimentos de inferioridade. Quem considerou absurda a manifestação de ontem, ainda não compreendeu o Brasil, este misterioso Brasil, sentimental e áspero, paciente e nervoso, mas - por fim - consciente da sua própria existência e da sua glória. (Jornal Do Brasil, 10 jun. 1962, p. 6).

\section{CONCLUSÃO}

Os jornais se tornaram, ao longo do tempo, fonte de consulta para diferentes áreas de pesquisa que buscam investigar o tema da construção nacional. Este trabalho busca, por meio da investigação dos meios de comunicação de massa - aqui res- 
tritos à imprensa escrita -, trazer mais elementos para o debate sobre globalização e identidade no campo do esporte.

Apesar de entendermos que o processo conhecido como globalização ainda está em curso, o que dificulta nossa análise pela proximidade do debate em tela, buscamos apontar alguns indícios para refletir como a globalização pode estar "deslocando", ou operando, tênues mudanças nas narrativas jornalísticas sobre o futebol no Brasil.

O que podemos notar, ao longo da análise das três Copas do Mundo aqui investigadas, é que as narrativas jornalísticas referentes ao "estilo nacional" apresentam continuidade independentemente das temporalidades analisadas nas três Copas. Ora temos o estilo de ginga e dribles valorizados, quando eficaz, ora esse estilo pode ser visto como negativo, diante das derrotas.

Em 1958, à medida que a seleção se vai aproximando do jogo final, as matérias passam a ressaltar de forma mais enfática o estilo nacional. Helal e Soares (2003, p. 7) reafirmam essa visão em seu estudo sobre a Copa de 2002: "Revelador observar como em um espaço curto de tempo o estilo vigoroso e duro na marcação passa a ser celebrado e o 'futebol que sambava com a bola no pé' é visto como um 'dramalhão'”. As narrativas da Copa de 1958 e 1962 não possuem um caráter homogêneo ao tratar o futebol brasileiro, o foco do debate jornalístico muda em função da trajetória da equipe na competição esportiva. Parece que a globalização, tão presente na Copa do Mundo de 2002, não atua necessariamente enfraquecendo a "pátria de chuteiras" - a própria estrutura da competição entre estados nacionais não permite isso - e o tema da nação-futebol ainda parece ser um bom motivo para conversas e para vender jornais.

O grande poder aglutinador dos eventos esportivos ${ }^{16}$ termina por criar uma nova forma de diálogo entre o futebol e os estados nacionais, sem que isso signifique, necessariamente, a perda de identidade. As pesquisas e os debates sobre recepção e os complexos e obscuros processos de codificação/decodificação devem ser realizadas tomando como objeto a construção das identidades no espaço da mídia (HALL, 2003). Nossa intenção é continuar aprofundando o debate, fazendo pesquisas sobre esse tema a partir de novas metodologias que auxiliem a comparação e o teste das hipóteses até aqui mapeadas.

16. A Copa do Mundo realizada na França no ano de 1998 foi o evento mais lucrativo de todos os tempos, assim como o mais assistido, com um público estimado de 2 bilhões em todo o mundo (SANTOS, 2000). 
The Brazilian soccer style is disappearing?

ABSTRACT: This article's objective is to analyze the texts published in the press on the World Cups of 1958 and 1962, and to compare them with the texts published in the World Cup of 2002. We used as sources, the editions of Jornal do Brasil during the World Cups of 1958, 1962 e 2002. The analysis of the journalistic narratives regarding the "national style" of playing soccer presents continuity. The narratives of the Cups of 1958 and 1962 don't have a homogeneous character when treating the Brazilian soccer, changing the focus of the debate in agreement with the overcome of the team's difficulties.

KEY WORDS: National identity; soccer; press; history of the World Cup.

\section{¿El fútbol-arte estas desapareciendo?}

RESUMEN: El artigo realiza analices comparativas de los periódicos sobre La Copa do Mundo de fútbol de 1958 e 1962 con la Copa de 2002. Utilizamos como material empírico las noticias del periódico Jornal do Brasil publicados durante las tres Copas. Las analices indican que las narrativas periodistas referentes al "fútbol-arte" poco cambiaran, ora tenemos el estilo de la gambeta e da ginga valorizados, cuando eficaz, ora el estilo puede ser percibido como negativo delante de la derrota. Las narrativas de las Copas de 1958 y 1962 no parecen tener un carácter homogéneo al retratar el fútbol brasileño, cambiando el foco del debate mediante la superación del equipo.

PALABRAS CLAVES: Identidad nacional; fútbol; prensa; historia de las Copas.

\section{REFERÊNCIAS}

ANDERSON, B. Imagined communities: reflections on the origins and spread of nationalism. New York: Verso, 1983.

ARCHETTI, E. El potrero, la pista y el ring: las patrias del deporte argentino. Buenos Aires: Fondo de Cultura Económica, 2001 .

. Masculinidades: fútbol, tango y polo en la Argentina. Buenos Aires: Antropofagia, 2003.

BARDIN, L. Análise de conteúdo. Lisboa: Edições 70, 1977.

BARTHOLO, T. L.; SOARES, A. J. G. Mané Garrincha como síntese da identidade do futebol brasileiro. Revista Movimento, v. I5, n. I, p. 169-192, jan. 2009.

CASTELLS, M. Paraísos comunais: identidade e significado na sociedade em rede. In: 0 poder da identidade - A era da informação: economia, sociedade e cultura. São Paulo: Paz e Terra, 1999, v. 2.

HALL, S. A identidade cultural na pós-modernidade. Rio de Janeiro: DP\&A, 2003. 
HELAL, R.; SOARES, A. J. O declínio da pátria de chuteiras: futebol e identidade nacional na Copa do Mundo de 2002. In: REUNIÃO ANUAL DA ASSOCIAÇÃO NACIONAL DE PROGRAMAS DE PÓS-GRADUAÇÃO EM COMUNICAÇÃO, 12. Recife, 2003. Anais... Recife: Compós, 2003 (CD-ROM XII Reunião Anual da Associação de Pós-Graduação em Comunicação, 2003).

HELAL, R.; SOARES, A. J.; LOVISOLO, H. A invenção do país do futebol: mídia, raça e idolotria. Rio de Janeiro: Mauad, 2001.

SANTOS, T. C. Globalização, mundialização e esporte: o futebol como megaevento. In: ALABARCES, P. (Org.). Peligro de gol: estudios sobre deporte y sociedad en América Latina. Buenos Aires: Clacso-AFDI, 2000.

SOARES, A. J.; LOVISOLO, H. Futebol: a construção do estilo nacional. Revista Brasileira de Ciências e Esporte, v. 25, n. I, p. 129-143, set. 2003.

VOGEL, A. O momento feliz, reflexões sobre o futebol e o ethos nacional. In: DAMATTA, R. (Org.). Universo do futebol: esporte e sociedade brasileira. Rio de Janeiro: Pinakotheke, 1982.

WHANNEL, G. Media sport stars: masculinities and moralities. London: Routledge, 2002.

Recebido: 19 ago. 2009

Aprovado: 5 abr. 2010

Endereço para correspondência:

Tiago Lisboa Bartholo

Rua Viúva Lacerda, 128, ap. 102 - Bairro Humaitá

Rio de Janeiro-RJ

CEP 2226I-050 